\title{
Hypothalamo-Pituitary Dysfunction in Patients With Chronic Subdural Hematoma
}

\author{
V. HÁNA ${ }^{1}$, M. KOSÁK ${ }^{1}$, V. MASOPUST ${ }^{2}$, D. NETUKA ${ }^{2}$, Z. LACINOVÁ $^{1}$, M. KRŠEK ${ }^{1}$, \\ J. MAREK ${ }^{1}$, L. PECEN ${ }^{3}$ \\ ${ }^{1}$ Third Department of Internal Medicine of General Faculty Hospital and Faculty of Medicine 1, \\ Charles University, Prague, Czech Republic, ${ }^{2}$ Department of Neurosurgery, Military Hospital and \\ Faculty of Medicine 1, Prague, Czech Republic, ${ }^{3}$ Institute of Computer Science, Academy of \\ Sciences of Czech Republic, Prague, Czech Republic
}

Received November 17, 2011

Accepted January 19, 2012

On-line January 31, 2012

\begin{abstract}
Summary
Relatively frequent pituitary hormone deficiencies are observed after traumatic brain injury (TBI) and subarachnoid hemorrhage (SAH) and according to the published studies the neuroendocrine consequenses of traumatic brain injury are underdiagnosed. In a cohort of 59 patients (49 males, mean age 68.3 years, 36-88 years) after evacuation of subdural hematoma (SDH) were evaluated hypothalamo-pituitary functions one week after surgery, after three months and after one year. Hypogonadism was present in $26 \%$ of patients in an acute phase, but in the majority had a transient character. Less than half of patients was $\mathrm{GH}$ deficient (GHD) according to the GHRH+arginine test. We did not find any serious case of hypocortisolism, hypothyroidism, diabetes insipidus centralis nor syndrome of inappropriate secretion of ADH (SIADH). Transient partial hypocortisolism was present in two cases, but resolved. We did not find relation between extension of SDH or clinical severity and development of hypopituitarism. In conclusion, in some patients with SDH growth hormone deficiency or hypogonadism was present. No serious hypocortisolism, hypothyroidism, diabetes insipidus nor SIADH was observed. The possibility of neuroendocrine dysfunction should be considered in patients with $\mathrm{SDH}$, although the deficits are less frequent than in patients after TBI or SAH.
\end{abstract}

\section{Key words}

Hypopituitarism • Subdural hematoma • Brain injury • Growth hormone deficiency

\section{Corresponding author}

V. Hána, Third Department of Internal Medicine of General
Faculty Hospital and Faculty of Medicine 1, Charles University, U nemocnice 1, 12808 Prague 2, Czech Republic. E-mail: vhana@If1.cuni.cz

\section{Introduction}

Traumatic brain injuries (TBI) are a serious health problem with a frequency of 235/100 000 persons per year (Tagliaferri et al. 2006). The patients are endangered in an acute phase, but also due to chronic consequences. Among these belong orthopedic, neurologic, psychiatric and also endocrinological complications. The percentage of pituitary deficits after traumatic brain injury is quite high and it is estimated that this sequelae is underdiagnosed. In the metaanalysis of Schneider et al. (2007) was hypopituitarism observed in 15.4-50 \% in a chronic phase after TBI (hypocorticalism in 2.6-19.2 \%, hypothyroidism in 1-10\%, hypogonadism in 1.9-20\% and growth hormone deficiency (GHD) in 5.9-32.7\%). After subarachnoid hemorrhage was the frequency of hypopituitarism even higher (37.5-55 \%).

Brain injury leads to brain edema, increased intracranial pressure, hemorrhages, microinfarctions, fibrosis in hypothalamus and pituitary (Harper et al. 1986, Salehi et al. 2007). In the late phase after TBI an autoimmune process in the pituitary is expected as the cause of some further hypopitutarisms (Tanriverdi et al. 2008). Similar conditions could be expected in patients with subdural hemorrhages, where preceding trauma, compression of the brain, shift of midline structures, 
possible compression of nutritive arteries and veins might compromise the structures of hypothalamo-pituitary endocrine unit. For these reasons we undertook this first study focused on neuroendocrine functions in patients operated for chronic subdural hematomas (SDH).

\section{Patients and Methods}

\section{Patients}

We examined in cooperation with Department of Neurosurgery 59 patients (49 males, mean age $68.3 \pm 12.87$ (S.D.) years, median age 72 years, range 3688 years, BMI $26.5 \mathrm{~kg} / \mathrm{m}^{2}$, range 18-37.6) operated for SDH. Forty-nine consecutive patients (41 males, mean age $66.8 \pm 13.0$ years, median age 70.0 years, range $36-88$ years, BMI $26.8 \mathrm{~kg} / \mathrm{m}^{2}$, range 18-37.6) were examined prospectively - first week after surgery, after three months and after 12 months. Ten patients ( 8 males, mean age $75.9 \pm 7.6$ years, median age 78 years, range $64-86$ years, BMI $25.2 \mathrm{~kg} / \mathrm{m}^{2}$, range 22.4-30.5) were evaluated after one year after surgery for SDH only.

In 13 patients in our group a trauma as clear cause of the subdural hematoma was found. In those patients a mean interval between the trauma and diagnosis of the subdural hematoma was 42.3 days (range 4-110 days). Alcohol abuse was present in the history of five patients.

\section{Methods}

The neurological status and its dynamics was evaluated before and after surgery for SDH. Midline structures shift and thickness of SDH was evaluated on CT scans.

In the mentioned intervals was evaluated basic biochemistry (minerals, renal functions, AST, ALT, ALP, GGT, bilirubin, glycemia) and hypothalamo-pituitary endocrine functions by measurement of basal values of hormones LH, FSH, testosterone/estradiol, freeT3, freeT4, TSH, prolactin, ACTH, IGF-1, cortisol and by dynamic testing. ACTH (Synacthen $250 \mu \mathrm{g}$ ) test, growth hormone releasing hormone $(\mathrm{GHRH})+$ arginine test $(1 \mu \mathrm{g} \mathrm{GHRH} / \mathrm{kg}$ of body weight i.v. $+30 \mathrm{~g}$ of arginine hydrochloride in 30 minute infusion; blood samples in 0 , $15,30,45,60,75,90 \mathrm{~min})$ and TRH test (200 $\mu \mathrm{g}$ TRH i.v.; blood samples in 0, 20, $60 \mathrm{~min}$ ) were used.

Standard biochemical tests were done on analyser Modular Analytics EVO (Hitachi, Japan). LH, FSH, estradiol, testosterone, prolactin, TSH, freeT3 and freeT4 were assayed by ADVIA Centaur (Siemens,
Healthcare Diagnostics Inc, Tarrytown, NY, USA), with chemiluminometric detection. FSH, LH, prolactin and TSH were determined by sandwich immunoanalysis with direct chemiluminometric technology; for estradiol, testosterone, free $\mathrm{T} 3$ and freeT4 competitive immunoanalysis, direct chemiluminometric technology was also used. Serum GH and IGF-I concentrations were measured by IRMA kits (IMMUNOTECH a.s., Prague, Czech Republic), following the manufacturer's instructions. Sensitivity for GH was $0.03 \mu \mathrm{g} / \mathrm{l}$. Sensitivity for IGF-I was $12 \mu \mathrm{g} / \mathrm{l}$. Serum cortisol levels were measured by commercial RIA kit ((IMMUNOTECH a.s., Prague, Czech Republic). Sensitivity was 10 nM. Plasma ACTH levels were measured by IRMA kits (Brahms Diagnostica, Hennigsdorf, Germany). Sensitivity was $1.2 \mathrm{pg} / \mathrm{ml}$. The intra- and interassay variability of all kits was less than $5.0 \%$ and $10.0 \%$ respectively.

As an adequate response in ACTH test was considered maximal cortisol value of $550 \mathrm{nmol} / 1$ (Clark et al. 1998). In GHRH+arginine test these cutoff levels for GHD were considered according to the patients' body mass index (BMI): with BMI $<25 \mathrm{~kg} / \mathrm{m}^{2}$ a peak $\mathrm{GH}<$ $11 \mu \mathrm{g} / \mathrm{l}$, with BMI $25-30 \mathrm{~kg} / \mathrm{m}^{2}$ a peak $\mathrm{GH}<8 \mu \mathrm{g} / \mathrm{l}$ and with BMI $>30 \mathrm{~kg} / \mathrm{m}^{2}$ a peak $\mathrm{GH}<4 \mu \mathrm{g} / 1$ (Ho et al. 2007). The increase in TSH after TRH at least $6 \mathrm{mU} / \mathrm{l}$ in males and females younger than 40 years of age and $2 \mathrm{mU} / 1$ in older than 40 years was defined as normal. Evaluation of central hypothyroidism was based on complex evaluation of thyroid hormones and TSH values. Central hypogonadism was evaluated only in relevant situations (patients after menopause and males with peripheral hypogonadism were excluded). Reference testosterone values in our laboratory are $9.9-28 \mathrm{nmol} / 1$ for men of age below 50 years. The evaluation of hypogonadism in older age is not straightforward. Although the decline of mean testosterone values with age is known, there are no generally accepted lower limits of normal values for elderly males (Wang et al. 2008). However there is consensus of clinically important cutoff for total testosterone of $8 \mathrm{nmol} / \mathrm{l}$, below which symptomatic males usually benefit from testosterone replacement and we decided to use this limit for patients over 50 years in this evaluation (Wang et al. 2008).

Evaluation of DI and SIADH was also performed. In patients where concomitant medication could influence the results of hormonal tests, the influenced axis was not evaluated (i.e. thyroxin replacement for peripheral hypothyroidism etc.).

All the protocol was in accordance with the 
Declaration of Helsinki (2000) of the World Medical Association and was approved by the Ethics Committee of General Faculty Hospital in Prague.

\section{Statistical analysis}

Statistical analysis was performed using SAS 9.2 software (SAS Institute Inc., Cary, NC, USA). The statistical results on comparing different time-points were calculated using a Wilcoxon Signed Rank test due to nongaussian distribution of many of analyzed parameters. Analysis of the relationship between various continuous variables was done using Spearman rank correlation coefficient. P-values were considered statistically significant at the 0.05 level.

\section{Results}

Maximal thickness of SDH and shift of the midline structures was described and quantified on preoperative CT scans. The maximal thickness of SDH was $33 \mathrm{~mm}$, minimal thickness was $9 \mathrm{~mm}$, mean $20 \pm 6$ (S.D.) $\mathrm{mm}$, median $20.5 \mathrm{~mm}$. Bilateral SDH was found in 11 cases. Mean shift of the midline structures in our group was $8.3 \pm 5.4 \mathrm{~mm}$ (range $0-20 \mathrm{~mm}$, median 8.8 ). Six patients had no shift of the midline structures - all of them had bilateral subdural hematomas.

Table 1. The frequency of each type of neurological finding before operation.

\begin{tabular}{lc}
\hline Clinical presentation & $\begin{array}{c}\text { Frequency } \\
\text { (No. of patients) } \\
\mathbf{n = 4 9}\end{array}$ \\
\hline Mild paresis (mono or hemi) & 16 \\
Moderate paresis (mono or hemi) & 4 \\
Severe paresis (mono or hemi) & 1 \\
Hemiplegia & 0 \\
Speech disorder & 5 \\
Alteration of the mental status + & 10 \\
Other neurological symptom ++ & 14
\end{tabular}

+ Alteration of the mental status - confusion, bradypsychia, ++ Other neurological symptom - headache, worse memory, dyscoordination, instability, falls, reduced unilateral sensitivity.

In collaboration with neurosurgeons a neurological status was evaluated (Table 1). Neurological status was evaluated before the operation and again soon after the operation in a prospectively followed group. The most common finding was mild mono or hemiparesis diagnosed in 16 patients. In 41 patients the operation led to complete restitution of the neurological deficit, in 8 patients was the reparation partial.

\section{Individual evaluation of hormonal status (Table 2)}

Analysis of the hormonal status immediately after the surgery revealed no evidence of hypocortisolism, hypothyroidism or diabetes insipidus. In 23 patients was the dynamic test in agreement with the diagnosis of GHD and in 9 cases central hypogonadism was present.

At 3 months' evaluation we found a subnormal response of cortisol in ACTH test (maximal cortisol value was slightly below $500 \mathrm{nmol} / \mathrm{l}$ ) in 2 patients, but control tests one month later showed a normal response. Central hypogonadism was present in two patients. Response of $\mathrm{GH}$ in GHRH+arginine test was insufficient in 16 cases.

Table 2. Evaluation of hormonal status - number of deficiencies.

\begin{tabular}{|c|c|c|c|}
\hline & \multicolumn{3}{|c|}{ Number of deficiencies } \\
\hline & $\begin{array}{l}\text { first week } \\
\text { after } \\
\text { surgery } \\
(n=49)\end{array}$ & $\begin{array}{c}\mathbf{3} \\
\text { months } \\
(\mathbf{n}=\mathbf{3 7})\end{array}$ & $\begin{array}{c}12 \\
\text { months } \\
(\mathrm{n}=32)\end{array}$ \\
\hline Hypocortisolism & 0 & $\begin{array}{l}2 \text { (mild, } \\
\text { transient) }\end{array}$ & 0 \\
\hline Hypothyroidism & 0 & 0 & 0 \\
\hline Central & 9 & 2 & 3 \\
\hline hypogonadism & $(n=35)$ & $(n=28)$ & $(n=25)$ \\
\hline $\begin{array}{l}\text { Growth hormone } \\
\text { deficiency }\end{array}$ & 23 & 16 & 15 \\
\hline $\begin{array}{l}\text { Hypogonadism }+ \\
\text { growth hormone } \\
\text { def. }\end{array}$ & 7 & 1 & 2 \\
\hline $\begin{array}{l}\text { Diabetes insipidus } \\
\text { centralis/SIADH }\end{array}$ & 0 & 0 & 0 \\
\hline
\end{tabular}

$\mathrm{n}$ - number of assessable patients.

At 12 months (analyzed both groups prospective and retrospective) no hypocortisolism or hypothyroidism was diagnosed, 3 patients were hypogonadal and 15 had GHD. There was no case of DI or SIADH in any phase of the study.

Both hypogonadism and GHD was present in 7 patients in an acute phase, 1 after 3 months (the second hypogonadal patient refused GHRH+arginine test) and in 2 patients after a year. 
Table 3. Hormonal values of the whole group ( $x \pm$ S.D.).

\begin{tabular}{lccc}
\hline & $\begin{array}{c}\text { First week after surgery } \\
(\mathbf{n = 4 9 )}\end{array}$ & $\begin{array}{c}\mathbf{3} \text { months } \\
(\mathbf{n = 3 7 )}\end{array}$ & $\begin{array}{c}\mathbf{1 2} \text { months } \\
(\mathbf{n = 3 2})\end{array}$ \\
\hline $\begin{array}{l}\text { Basal cortisol (nmol/l) } \\
\text { Maximal cortisol in ACTH }\end{array}$ & $517 \pm 130$ & $445 \pm 142 \S$ & $431 \pm 121 \S$ \\
test (nmol/l) & $981 \pm 209$ & $917 \pm 217$ & $903 \pm 184$ \\
Free T4 (pmol/l) & $15.1 \pm 2.4$ & $14.0 \pm 2.4$ & $15.1 \pm 1.7$ \\
Testosterone (nmol/l) & $12.0 \pm 5.1$ & $15.7 \pm 5.7$ & $13.4 \pm 5.6$ \\
Maximal TSH in TRH test & $8.1 \pm 5.2$ & $9.8 \pm 5.8 \S \S \S$ & $11.1 \pm 7.0 \S \S \S$ \\
\hline
\end{tabular}

$\S \mathrm{P}<0.01$ - against day $0, \S \S \S \mathrm{P}<0.05 \%$ - against day 0 .

Head trauma as a clear cause of subdural hematoma was present in the history of 13 patients. In two of these patients was GHD present permanently and in four other was GHD and/or hypogonadism present transiently.

There was a problematic compliance during the study period in some patients and it increased with time. Although we contacted all the patients, only part of them agreed with repeated examination. Some non-compliant SDH patients did not feel health problems and others suffered from some other concomitant disease and refused further examination after 3 and 12 months.

Analysis of the hormonal status of the whole group (Table 3)

Statistical analysis of the maximal response of GH in GHRH+arginine test showed different behavior for values in prospective individual assessment and for results of group analysis and this disabled statistical evaluation.

Analyzing the relationship between various variables and the clinical status, we found significant correlation between basal TSH value and maximal TSH value in TRH test $(\mathrm{r}=0.82, \mathrm{p}<0.001)$. There was no correlation between midline structures shift, which could represent the severity of trauma of midline structures, and the hormonal values nor any other analyzed parameters.

\section{Discussion}

The majority of clinical studies have demonstrated that TBI and SAH frequently cause neuroendocrine dysfunction in adults and also in children and adolescents (Čáp 2006, Schneider et al. 2007, Aleksijevič et al. 2010, Krahulik et al. 2010, Zapletalová et al. 2010, Kosák and Hána 2011). In accordance with this observation is also the recently published analysis of large German and Austrian registry (Schneider et al. 2011). The structures of hypothalamus and pituitary appear to be very sensitive to trauma and vascular insult in the acute phase (Benvenga et al. 2000, Salehi et al. 2007) and the participation of autoimmune process in the chronic phase is assumed (Tanriverdi et al. 2010a). Relationship between severity of trauma and hormonal dysfunction have been observed by some (Bondanelli et al. 2004, Klose et al. 2007) but not by others (Agha et al. 2004, Aimaretti et al. 2005, Schneider et al. 2006). It has been clearly demonstrated that even mild TBI can cause neuroendocrine dysfunction (Tanriverdi et al. 2010b). Hypothalamo-pituitary dysfunction was described even in association with brain operation of distant structures (DeMarinis et al. 2006).

This is the first study focused on patients with chronic subdural hematoma in which we prospectively evaluated neuroendocrine functions during one year after evacuation of SDH. We did not observe in our cohort during the whole study any serious dysfunction of adrenocortical or thyroid axes and no diabetes insipidus or SIADH, except of two cases of subnormal cortisol response in ACTH test in 3 months' testing. These two patients had maximal stimulated cortisol slightly below $500 \mathrm{nmol} / 1$, but in a control test one month later was the response again normal.

Slight, but significant increase of mean basal cortisol first week after surgery could be simply a marker of stress.

Similarly to TBI studies we observed quite frequently dysfunction in gonadotrophic axis and growth hormone secretion, especially in an acute phase. Growth hormone deficiency according to GHRH+arginine test 
was the most frequent in our group. Recovery of gonadotrophin secretion after the acute phase appeared in the majority of patients. The time course of central hypogonadism was recently exactly described in an acute phase after brain trauma. Study of Wagner et al. (2010) revealed that within 10 days of complicated mild, moderate, and severe TBI, testosterone suppression occured in all men and estrogen suppression occured in over $40 \%$ of women.

Chronic subdural hematoma most frequently occurs in older males (Kanat et al. 2010). We are aware that evaluation of gonadotrophin axis and especially of $\mathrm{GH}$ secretion, in our cohort with a mean age of 68 years is rather complicated. The activity of both axes declines with age and is influenced by non-endocrine factors like for instance comorbidities, obesity etc. It is likely that function of gonadotrophic axis is a marker of general health (Araujo et al. 2011). Establishing in this group of patients with various comorbidities the diagnosis of GHD and hypogonadism caused strictly by $\mathrm{SDH}$ is sometimes impossible. Replacement therapy of these axes in older people is for the mentioned reasons also limited. Nevertheless not all patients were of advanced age. Evaluating patients younger than 60 years of age there was GHD in an acute phase in 4/14 (GHD/evaluated patients under 60), after 3 months $3 / 10$ and after 12 months in $2 / 8$ patients. In one 36 years old patient with confirmed severe GHD was GH replacement commenced.

We also analyzed the relationship between extension of SDH or clinical severity and development of hypopituitarism, but we did not find any association. From our results it was not possible to identify patients more susceptible to hypopituitarism after SDH on the basis of their clinical status or a CT scan.

Comparing results in our cohort with TBI or SAH studies is complicated by substantially higher age and more confounding comorbidities in our group. Nevertheless it is obvious that we observed less severe neuroendocrine dysfunction after $\mathrm{SDH}$ than it was published after TBI. In a prospective study after TBI had subnormal cortisol response $16 \%$ of patients in an acute phase and $18 \%$ after 6 and 12 months and hypothyroidism was present in $2 \%$ (Agha et al. 2005). We observed no serious deficiency in corticotrophic axis. We also did not observe disturbance in thyrotrophic axis, or diabetes insipidus or SIADH. Comparing the gonadotrohic axis and GH secretion is impossible for the above mentioned reasons of different groups of patients.

How to explain less pituitary dysfunction in
$\mathrm{SDH}$ patients in relation to TBI and SAH? We propose that there could be several reasons. As the chronic SDH is typical for older persons, some brain atrophy diminishes the pressure of SDH on brain structures. The other reason could be in a slowly developing SDH (most frequently for at least several weeks) providing time for adaptation of possible vascular mechanisms, which could cause the injury of hypothalamic and pituitary structures. We must also admit that not all published studies prove a high frequency of hypopituitarism after brain insult. Klose et al. (2010) did not find any chronic hypopituitarism in 62 patients after subarachnoid hemorrhage and recently published study evaluating neuroendocrine functions in children after structural TBI in early childhood did not find any permanent hypopituitarism in almost 200 children (Heather et al. 2012).

We think that patients with SDH, especially those with head trauma in the history, should be managed like patients with mild TBI (Tanriverdi et al. 2010b). Despite we did not find any hypocortisolism in our cohort, we are aware of limited cohort of our patients and we believe that an evaluation of ACTH axis should be done in an acute phase on clinical basis and measurement of basal cortisol. Measurement of free thyroid hormones should be done in this phase also. In the chronic phase all the pituitary hormones and hormones of regulated glands should be measured and in clinical context using of appropriate dynamic tests should be considered.

In conclusion, results of our study showed no serious hypocortisolism, hypothyroidism, diabetes insipidus or SIADH in patients operated for chronic subdural hematoma. Severe GHD was present in less than half of patients. Central hypogonadism was diagnosed in a quarter of patients in an acute phase, but recovered in the majority of them during the follow up. The possibility of neuroendocrine dysfunction should be considered in patients with $\mathrm{SDH}$, although the deficits are less frequent than in patients after TBI or SAH.

\section{Conflict of Interest}

There is no conflict of interest.

\section{Acknowledgements}

We thank doctors L. Pekař and R. Leško for referring patients. We very acknowledge analyses of blood samples managed by Ing. Springer and Mgr. Uhrová and technical laboratory assistance of Hana Frydlová. The project was supported by a grant of Czech Ministry of Health NS 9794-4. 


\section{References}

AGHA A, ROGERS B, SHERLOCK M, O'KELLY P, TORMEY W, PHILLIPS J, THOMPSON CJ: Anterior pituitary dysfunction in survivors of traumatic brain injury. J Clin Endocrinol Metab 89: 4929-4936, 2004.

AGHA A, PHILLIPS J, O'KELLY P, TORMEY W, THOMPSON CJ: The natural history of post-traumatic hypopituitarism: implications for assessment and treatment. Am J Med 118: 1416.e1-1416.e7, 2005.

AIMARETTI G, CORNELI G, RAZZORE P, BELLONE S, BAFFONI C, ARVAT E, CAMANNI F, GHIGO E: Comparison between insulin-induced hypoglycemia and growth hormone (GH)-releasing hormone + arginine as provocative tests for the diagnosis of GH deficiency in adults. $J$ Clin Endocrinol Metab 83: 1615-1618, 1998.

AIMARETTI G, AMBROSIO MR, Di SOMMA C, GASPERI M, CANNAVÒ S, SCARONI C, FUSCO A, DEL MONTE P, DE MENIS E, FAUSTINI-FUSTINI M, GRIMALDI F, LOGOLUSO F, RAZZORE P, ROVERE S, BENVENGA S, DEgli UBERTI EC, De MARINIS L, LOMBARDI G, MANTERO F, MARTINO E, GIORDANO G, GHIGO E: Residual pituitary function after brain injury-induced hypopituitarism: a prospective 12-month study. J Clin Endocrinol Metab 90: 6085-6092, 2005.

ALEKSIJEVIČ D, ZAPLETALOVÁ J, SMOLKA V, KLÁSKOVÁ E, WIEDERMANN J, KRAHULÍK D, VAVERKA J, FRYŠÁK Z: Neuro-endocrine dysfunction in children and adolescents after brain injury (in Czech). Cesk Slov Neurol Neurochir 73: 409-414, 2010.

ARAUJO AB, DIXON JM, SUAREZ EA, MURAD MH, GUEY LT, WITTERT GA: Endogenous testosterone and mortality in men: a systematic review and meta-analysis. J Clin Endocrinol Metab 96: 3007-3019, 2011.

BENVENGA S, CAMPENNÍ A, RUGGERI RM, TRIMARCHI F: Clinical review 113: Hypopituitarism secondary to head trauma. J Clin Endocrinol Metab 85: 1353-1361, 2000.

BONDANELLI M, DE MARINIS L, AMBROSIO MR, MONESI M, VALLE D, ZATELLI MC, FUSCO A, BIANCHI A, FARNETI M, DEGLI UBERTI EC: Occurrence of pituitary dysfunction following traumatic brain injury. J Neurotrauma 21: 685-696, 2004.

CLARK PM, NEYLON I, RAGGATT PR, SHEPPARD MC, STEWART PM: Defining the normal cortisol response to the short Synacthen test: implications for the investigation of hypothalamic-pituitary disorders. Clin Endocrinol (Oxf) 49: 287-292, 1998.

ČÁP J: Hormonal diseases after traumatic brain injury (in Czech). Vnit Lék 52: 941-946, 2006.

DEMARINIS L, FUSCO A, BIANCHI A, AIMARETTI G, AMBROSIO MR, SCARONI C, CANNAVO S, DI SOMMA C, MANTERO F, DEgLi UBERTI EC, GIORDANO G, GHIGO E: Hypopituitary findings in patients with primary brain tumors 1 year after neurosurgical treatment: preliminary report. $J$ Endocrinol Invest 29: 516-522, 2006.

HARPER CG, DOYLE D, ADAMS JH, GRAHAM DI: Analysis of abnormalities in pituitary gland in non-missile head injury: study of 100 consecutive cases. J Clin Pathol 39: 769-773, 1986.

HEATHER NL, JEFFERIES C, HOFMAN PL, DERRAIK JG, BRENNAN C, KELLY P, HAMILL JK, JONES RG, ROWE DL, CUTFIELD WS: Permanent hypopituitarism is rare after structural traumatic brain injury in early childhood. J Clin Endocrinol Metab 97: 599-604, 2012.

HO KK on behalf of the 2007 GH Deficiency Consensus Workshop Paticipants: Consensus guidlines for the diagnosis and treatment of adults with GH deficiency II: a statement of the GH Research Society in association with the European Society for Pediatric Endocrinology, Lawson Wilkins Society, European Society of Endocrinology, Japan Endocrine Society, and Endocrine Society of Australia. Eur J Endocrinol 157: 695-700, 2007.

KANAT A, KAYACI S, YAZAR U, KAZDAL H, TERZI Y: Chronic subdural hematoma in adults: why does it occur more often in males than females? Influence of patient's sexual gender on occurrence. J Neurosurg Sci 54: 99$103,2010$.

KLOSE M, JUUL A, STRUCK J, MORGENTHALER NG, KOSTELJANETZ M, FELDT-RASMUSSEN U: Acute and long-term pituitary insufficiency in traumatic brain injury: a prospective single-centre study. Clin Endocrinol (Oxf) 67: 598-606, 2007.

KOSÁK M, HÁNA V: Hypothalamo-pituitary dysfunction following traumatic brain injury and spontaneous subarachnoid haemorrhage (in Czech). Cesk Slov Neurol Neurochir 74: 286-291, 2011. 
KRAHULIK D, ZAPLETALOVA J, FRYSAK Z, VAVERKA M: Dysfunction of hypothalamic-hypophysial axis after traumatic brain injury in adults. $J$ Neurosurg 113: 581-584, 2010.

SALEHI F, KOVACS K, SCHEITHAUER BW, PFEIFER EA, CUSIMANO M: Histologic study of the human pituitary gland in acute traumatic brain injury. Brain Inj 21: 651-656, 2007.

SCHNEIDER HJ, SCHNEIDER M, SALLER B, PETERSENN S, UHR M, HUSEMANN B, VON ROSEN F, STALLA GK: Prevalence of anterior pituitary insufficiency 3 and 12 months after traumatic brain injury. Eur $J$ Endocrinol 154: 259-265, 2006.

SCHNEIDER HJ, KREITSCHMANN-ANDERMAHR I, GHIGO E, STALLA GK, AGHA A: Hypothalamopituitary dysfunction following traumatic brain injury and aneurysmal subarachnoid hemorrhage: a systematic review. JAMA 298: 1429-1438, 2007.

SCHNEIDER HJ, SCHNEIDER M, KREITSCHMANN-ANDERMAHR I, TUSCHY U, WALLASCHOFSKI H, FLECK S, FAUST M, RENNER CI, KOPCZAK A, SALLER B, BUCHFELDER M, JORDAN M, STALLA GK: Structured assessment of hypopituitarism after traumatic brain injury and aneurysmal subarachnoid hemorrhage in 1242 patients: the German interdisciplinary database. J Neurotrauma 28: 1693-1698, 2011.

TAGLIAFERRI F, COMPAGNONE C, KORSIC M, SERVADEI F, KRAUS J: A systematic review of brain injury epidemiology in Europe. Acta Neurochir 148: 255-268, 2006.

TANRIVERDI F, DE BELLIS A, BIZZARRO A, SINISI AA, BELLASTELLA G, PANE E, BELLASTELLA A, UNLUHIZARCI K, SELCUKLU A, CASANUEVA FF, KELESTIMUR F: Antipituitary antibodies after traumatic brain injury: is head trauma-induced pituitary dysfunction associated with autoimmunity? Eur $J$ Endocrinol 159: 7-13, 2008.

TANRIVERDI F, DE BELLIS A, BATTAGLIA M, BELLASTELLA G, BIZZARRO A, SINISI AA, BELLASTELLA A, UNLUHIZARCI $\mathrm{K}$, SELCUKLU A, CASANUEVA FF, KELESTIMUR F: Investigation of antihypothalamus and antipituitary antibodies in amateur boxers: is chronic repetitive head trauma-induced pituitary dysfunction associated with autoimmunity? Eur J Endocrinol 162: 861-867, 2010a.

TANRIVERDI F, UNLUHIZARCI K, KELESTIMUR F: Pituitary function in subjects with mild traumatic brain injury: a review of literature and proposal of a screening strategy. Pituitary 13: 146-153, $2010 \mathrm{~b}$.

WAGNER J, DUSICK JR, MCARTHUR DL, COHAN P, WANG C, SWERDLOFF R, BOSCARDIN WJ, KELLY DF: Acute gonadotroph and somatotroph hormonal suppression after traumatic brain injury. $J$ Neurotrauma 27: 1007-1019, 2010.

WANG C, NIESCHLAG E, SWERDLOFF R, BEHRE HM, HELLSTROM WJ, GOOREN LJ, KAUFMAN JM, LEGROS JJ, LUNENFELD B, MORALES A, MORLEY JE, SCHULMAN C, THOMPSON IM, WEIDNER W, WU FC: Investigation, treatment and monitoring of late-onset hypogonadism in males: ISA, ISSAM, EAU, EAA and ASA recommendations. Eur J Endocrinol 159: 507-514, 2008.

ZAPLETALOVÁ J, ALEKSIJEVIC D, SMOLKA V, KRAHULÍK D, FRYŠÁK Z: Post-traumatic hypopituitarism in children and adolescents (in Czech). Cesk Slov Neurol Neurochir 73: 398-401, 2010. 